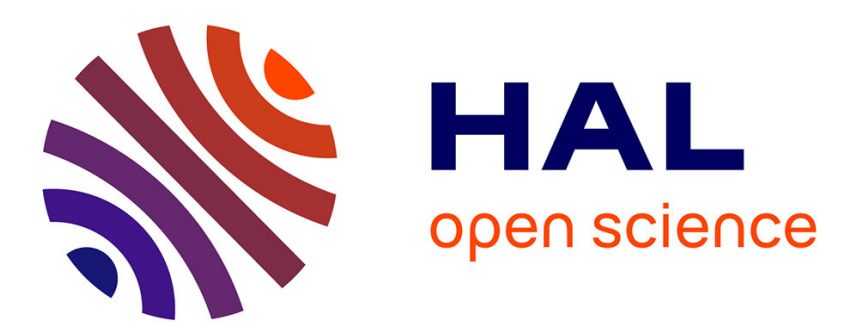

\title{
Time and Temperature Dependence of Amorphous Polymer Dynamic Properties after a Small Static Deformation
}

B. Haidar, A. Vidal

\section{- To cite this version:}

B. Haidar, A. Vidal. Time and Temperature Dependence of Amorphous Polymer Dynamic Properties after a Small Static Deformation. Journal de Physique IV Proceedings, 1996, 06 (C8), pp.C8-567-C8570. 10.1051/jp4:19968122 。 jpa-00254553

HAL Id: jpa-00254553

https://hal.science/jpa-00254553

Submitted on 1 Jan 1996

HAL is a multi-disciplinary open access archive for the deposit and dissemination of scientific research documents, whether they are published or not. The documents may come from teaching and research institutions in France or abroad, or from public or private research centers.
L'archive ouverte pluridisciplinaire HAL, est destinée au dépôt et à la diffusion de documents scientifiques de niveau recherche, publiés ou non, émanant des établissements d'enseignement et de recherche français ou étrangers, des laboratoires publics ou privés. 


\title{
Time and Temperature Dependence of Amorphous Polymer Dynamic Properties after a Small Static Deformation
}

\author{
B. Haidar and A. Vidal \\ Institut de Chimie des Surfaces et Interfaces, CNRS, P.O. Box 2488, 68057 Mulhouse, France
}

\begin{abstract}
The physical aging concept is generally used to explain the typical behavior of amorphous glassy materials such as amorphous polymers after different annealing or temperature quenching. In this work it is evidenced by measuring, on already aged specimens, the effect of deformation on the dynamic mechanical properties of several amorphous polymers (polycarbonate, polyetherimide and a styrene butadiene copolymer). For a static extension of $3 \%, E^{\prime}$ at an amplitude of $\sim 0.01 \%$ was determined from 0.4 to $25 \mathrm{~Hz}$, and for aging times, $t_{e}$, in the 10 to $7000 \mathrm{~s}$ range or longer. Such data determined at different temperatures were used to evaluate the aging rate $d \log E^{\prime} / d \log t_{e}$, which was found to be independent of frequency and $t_{e}$ over the ranges covered. Aging rate was found to increase with increasing temperature towards the nominal $T_{g}$ of the polymer. Several peaks were observed and attempts were made to attribute them to different moieties of the polymer chains by comparison of the secondary relaxations. Furthermore, the effects exerted by small solid particles or short fibers in composite materials based on the same polymer matrix were discussed.
\end{abstract}

\section{INTRODUCTION}

Amorphous glassy materials are seldom at thermodynamic equilibrium, and so are their physical properties. Their relaxation towards equilibrium is referred to as physical aging in the case of polymers but as structural relaxation, stabilization,... for other organic or inorganic glasses. This diversity reflects the wide range of disciplines on which physical aging has an important impact. "Physical" aging (to be distinguished from other time-dependent processes) is of considerable practical importance in the domain of the glassy state relaxation. Particularly in the case of polymer, where prediction of the long term behavior and the change in physical properties is a real need.

In glassy polymeric materials physical aging results predominentely from the heating of the sample above its $T_{g}$, which indicates a close connection between aging and glass transition. After a rapid cooling from above to below $T_{g}$, physical aging is commonly quantified by specific volume[1], storage modulus[2-3], intermittent creep or relaxation measurements... [4-5]. For such undeformed specimens, quenched from rubbery to glassy state, predictions supported by certain experimental data [4] have shown that physical aging occurs between the $T_{g}$ and $T_{\beta}$ of the polymer. Beyond these limits, the rate of aging goes to zero. In polymer science, this type of aging is commonly explained, by a progressive decrease in the mobility of short segments.

It is of importance to know the effect of the applied deformation on the physical properties of glassy polymers and their dependence on aging time, much less attention has been given to this deformation related aspect of physical aging. It is, however, known that applied stress gives rise to an increase of segmental mobility, a behavior which is referred to as "rejuvenation", "de-aging" or "softening" process. Thereafter and under constant force or strain conditions, segmental mobility decreases, aging or hardening proceeds anew. The general accepted explanation for this effects attributes it to a change in volume or in free volume. The primary purpose of the present study is to determine aging rate for several materials based on amorphous polymers subjected to a moderate static extension $(2-3 \%)$ over a wide range of temperatures covering or approaching the nominal $T_{g}$ of the polymer. 


\section{EXPERIMENTAL}

Three different commercially available polymers were selected in this study. While all of them are amorphous, they differ largely by their respective glass transition temperatures ( $T_{g}$ difference is about $200^{\circ} \mathrm{C}$ ) : PC, polycarbonate bisphenol-A (Laxane, General Electric); PEI, polyetherimide (Ultem, General Electric) and SBR, poly(styrene-co-butadiene) (Buna 1500, Hüls) which was crosslinked by dicumyl peroxide $(2 \% \mathrm{w} / \mathrm{w})$. In addition, two composites were also used: a PC samples filled with $30 \% \mathrm{w} / \mathrm{w}$ of unidirectional oriented short glass fibers was kindly provided by the PC manufacturer and SBR filled with $33 \% \mathrm{w} / \mathrm{w}$ of carbon black (N330, Degussa) compounded in our laboratory and crosslinked according to the same procedure used for the pure SBR.

Physical aging measurements were performed using different equipments : Dynastat, Metravib and DMTA. The sample to be analyzed was mounted between grips then after a selected temperature was reached, specimen was subjected to a 0.2 to $0.3 \%$ tensile strain, dynamic moduli were then measured at an amplitude lower then $0.1 \%$ and for frequencies in the 0.1 to $25 \mathrm{~Hz}$ range. It was verified that, under this regime, modulus $\left(E^{\circ}\right)$ is time-independent. Next, the sample while stretched to $2-3 \%$ and maintained under relaxation conditions throughout the experiment, was modulated intermitently with a sinusoidal tensile strain (amplitude $<0.1 \%$, frequency 0.1 to $25 \mathrm{~Hz}$ ). Such measurements were performed over a large range of temperatures overlapping the glass transition temperature of the polymers under analysis.

\section{RESULTS}

\subsection{Dermination of aging rate}

Figure 1, shows a typical results obtained at $150^{\circ} \mathrm{C}$ using double logarithmic coordinates, of the modulifrequency dependence for unstretched specimen, $E^{\circ}$, and at different mentioned elapsed times, $t_{e}$, after the application of static deformation of $3 \%$.

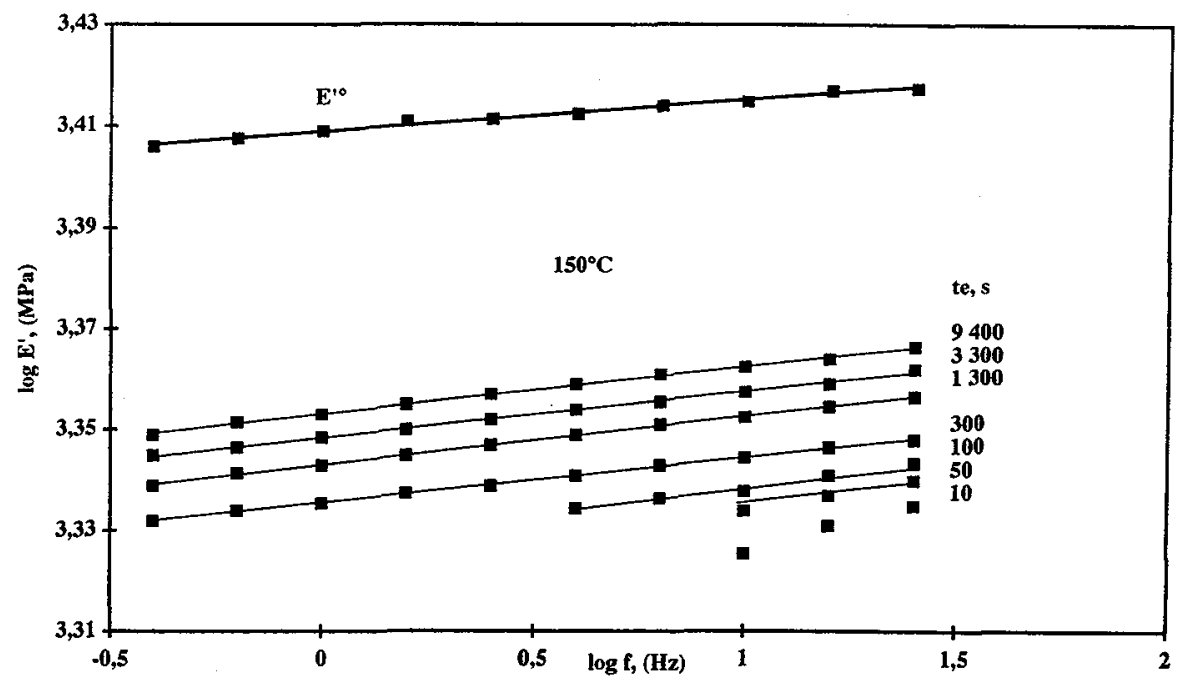

Figure 1: Frequency dependence of $E^{\prime \prime}$, at seven values of aging time, $t_{e}$, after a $3 \%$ strain. The uppermost line shows $E^{\prime \circ}$ determined on a slightly deformedspecimen $(0.25 \%)$.

It is remarkable that frequency-dependence of the modulus $E^{\prime}$ is virtually independent of the aging time (lines in figure 1 are parallels). Thus, it is most useful to evaluate the aging rate by plotting $E$ ' at any frequency (for instance at $5 \mathrm{~Hz}$ ) versus $\log t_{e}$. This plot yields straight lines whose slope is the aging rate at the considered temperature.

At all temperatures and frequencies covered in the present experiments, aging rate $d \log E^{\prime} / d \log t_{e}$ was found to be independent of frequency and aging time. 


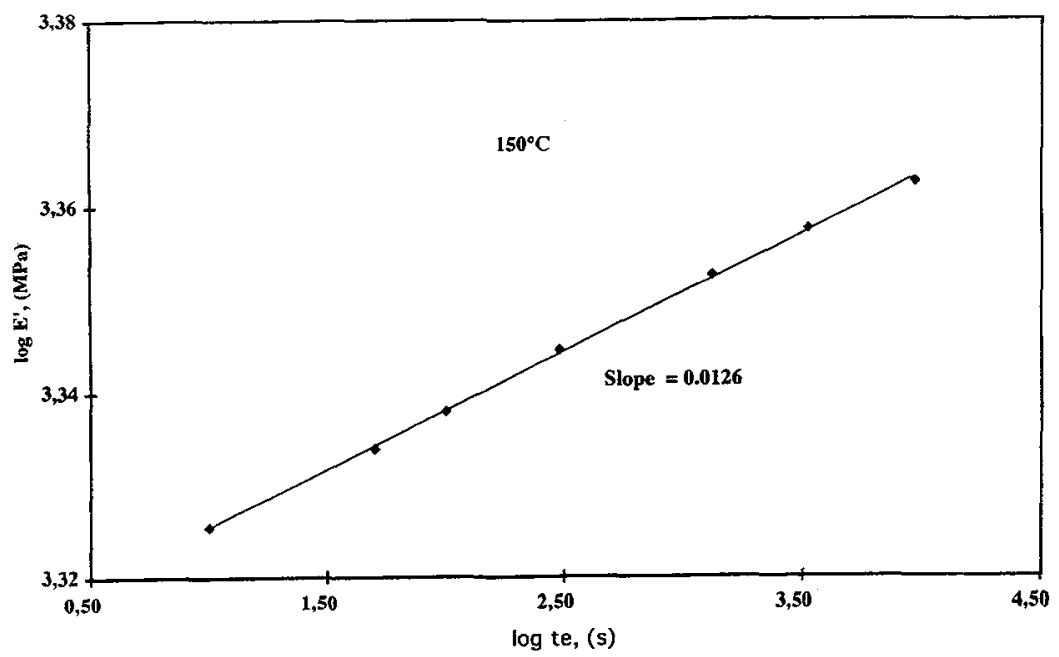

Figure 2: Crossplot of data at $5 \mathrm{~Hz}$ from figure 1, the slope of the line is the aging rate at $150^{\circ} \mathrm{C}$

\subsection{Temperature dependence of the aging rate at the polymers glass transitions}

The three polymers covered in this study have a large difference in their glass transition temperature as determined by the maxima of $\tan \delta$ at $10 \mathrm{~Hz}$ : 235,145 and $-35^{\circ} \mathrm{C}$ for PEI, PC and SBR, respectively. Curves shown in figure 3 provide the aging rate dependence with temperature, or more precisely, the reduced temperature $\left(T-T_{g}\right)$.

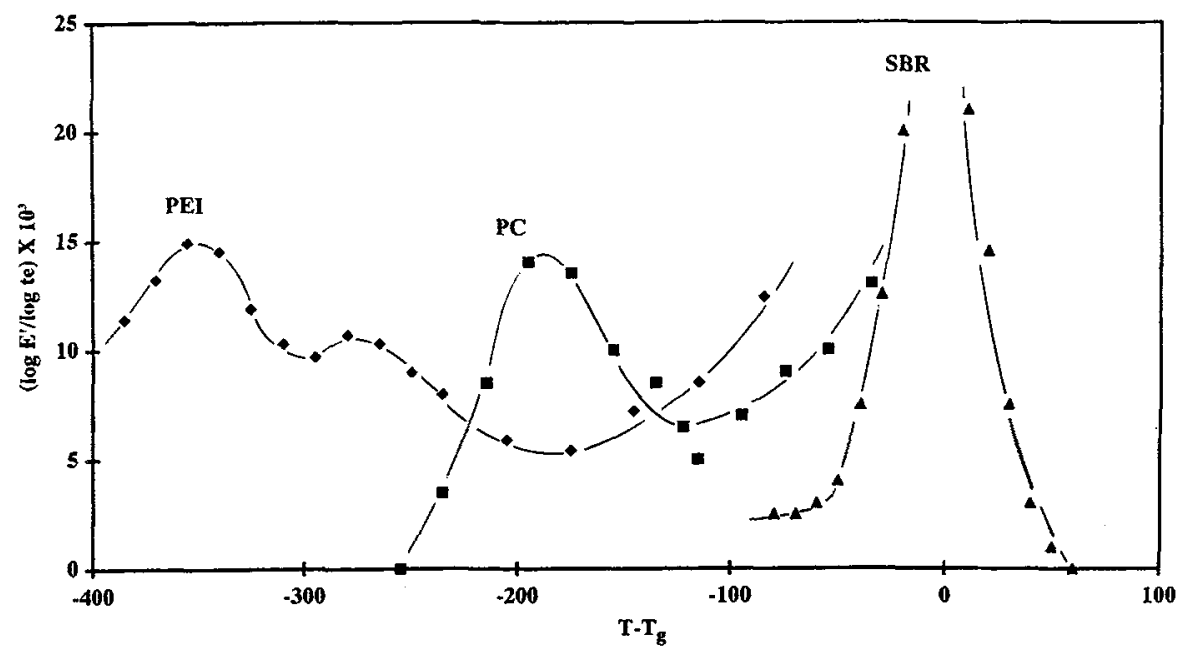

Figure 3: Aging rate as a function of the reducedtemperature for the three studied polymers.

Depending on the polymer under study aging rate, at temperatures below glass transition, may exhibit different temperature dependence. This results is discussed elsewhere [6]. However, when measurement are made at temperatures approaching the nominal glass transition of the polymer, aging rate seems invariably to increase with increasing temperature and presumably goes through a maximum at the polymer $T_{g}$, though maxima were not detectable because the specimens were highly unstable in this temperature domaine. However, it was verified on crosslinked SBR that aging rate tends to zero for temperatures perceptibly above $T_{g}$. 


\subsection{Aging rate in composites materials.}

Table 1 compares the aging rate values of the composite materials with their parent polymer at constant temperatures. Temperatures were chosen far enough above and below the polymer $T_{g}$ to consider its effect as negligable. It is remarkable that within the glassy state $\left(T<T_{g}\right)$ of both polymers under study, the addition of solid particles or fibers to the matrix induces an increase in the aging rate of the composite compared to that of its parent polymer. However, although at temperatures above $T_{g}$ unfilled rubber does not show naturally any aging behavior (aging rate is virtually equal to zero) filled SBR exhibits an experimentally detectable aging.

Table 1 : Aging rate measured at the indicated reduced temperatures for composites and raw polymers.

Table 1 : Aging rate measured at the indicated reducedtemperatures for composites and raw polymers.
\begin{tabular}{|c|c|c|}
\hline Material & $T-T_{g},\left({ }^{\circ} \mathrm{C}\right)$ & Aging rate, $\left[\operatorname{dlog} E(M P a) / d \log t_{e}(s)\right] \times 10^{3}$ \\
\hline PC & -70 & 8.5 \\
\hline PC + glasse fiber & -70 & 11.2 \\
\hline SBR & -70 & 2.5 \\
\hline SBR + carbon black & -70 & 5.3 \\
\hline SBR & +70 & 0 \\
\hline SBR + carbon black & +70 & 4.2 \\
\hline
\end{tabular}

\section{CONCLUDING REMARKS}

If it is widely approved that physical aging can be provoked by temperature quenching over the polymer $T_{g}$, the present study demonstrates that aging may occur by imposing macroscopic deformation too. Results presented in this paper draw the attention on the fact that imposed deformation on an aged specimen of glassy polymer provokes, first, its de-aging (softening) and then its subsequent aging (hardening). Moving the polymer away from its thermodynamic equilibrium seems to be the necessary condition for physical aging to be experimentally detectable. This detection can be made essentially during the return of the specimen towards its thermodynamic equilibrium, after a temperature change but also after a macroscopic deformation.

Physical aging increases with increasing temperature towards glass transition for all studied polymers. This reflects the progressive increase in segmental mobility which at, and above, $T_{g}$ becomes too rapid to be observed by ordinary experimental techniques. Still, at $T>T_{g}$ it has been observed on a crosslinked polymer sample that physical aging decreases with temperature. What is detected in this case is the tail of the relaxation, it decreases with increasing segmental mobility. It is remarkable that physical aging can still be detectable up to temperatures as high as 30 to $50^{\circ} \mathrm{C}$ above $T_{g}$.

Such behavior towards $T_{g}$ is drastically opposite to what is predicted and supported by some data in the literature as it has been mentioned in the introduction. This contradiction may be attributed to two factors : i) it is experimentally difficult for conventional temperature quenching measurements to detect high aging rate, i.e. the rate of temperature quenching will always be slower than the rate of physical aging; ii) for strained specimens aging is physically different and undoubtedly more complex than that of isotropic specimens.

Aging of composites seems to be affected by the presence of solid particles or fibers in a very peculiar way, governed by the special conformation of the polymer chain on the solid surface. In the interfacial region, segments have higher mobility thanthe same unfilled polymer in the glassy state. On the contrary, at $T>T_{g}$, segments at the interface have much more restricted mobility than the free rubber. Polymer/solid interactions seem to impose their law on the organization of the interfacial region inducing a peculiar behavior, certainely anisotropic in nature in term of aging and de-aging under deformation.

The phenomenological approach to explain aging which is purely a thermal history-dependent process, is surely adequate for many applications, however, a global treatment of non thermal perturbation of glassy polymer has not yet been developed. Theoretical understanding of glassyness and consequently of physical aging are surely needed in the first place before expecting to clarify the anisotropic peculiar situation of the chains located at a solid/polymer interface.

\section{References}

[1] Kovacs, A.J. Adv. Polym. Sci., 3 (1963) 394-505

[2] Kovacs, A.J, Stratton, R.A. and Ferry, J.D., J. Phys. Chem., 67 (1963) 152-161

[3] Haidar, B. and Smith, T.L., Macromol., 23 (1990) 3710-3713

[4] Struik, L.C.E., Physical aging in amorphous polymers (Elsevier, Amesterdam, 1978)

[5] McKenna, G.B. and Kovacs, A.J., Polym. Eng. Sci. 24, (1984) 1138-1143

[6] Haidar, B. and Smith, T.L., Polymer., 31 (1990) 1904-1907 